\title{
Effects of age and leg length upon central loop of the Gastrocnemius-soleus H-reflex latency Shahram Sadeghi*1, Mohammadrezaalavian Ghavanini ${ }^{2}$, Alireza Ashraf ${ }^{2}$ and Peyman Jafari ${ }^{3}$
}

Address: ${ }^{1}$ Pain research group, multidisciplinary pain clinic of iran jahad danesh gahi, no 31, karimkhan zand ave. shahid hosseini alley, Tehran, Iran, ${ }^{2}$ Department of physical medicine and rehabilitaton, shiraz medical school, zand avenue, Shiraz, Iran and ${ }^{3}$ Department of biostatistics, shiraz medical school, zand avenue, Shiraz, Iran

Email: Shahram Sadeghi* - SHSADEGHI@SUMS.AC.IR; Mohammadrezaalavian Ghavanini - alavianm@sums.ac.ir; Alireza Ashraf - ALIREZAASHRAF@YAHOO.COM; Peyman Jafari - PJBIOSTAT@YAHOO.CO.UK

* Corresponding author

Published: 03 September 2004

BMC Neurology 2004, 4:II doi:10.1 I86/147/-2377-4-II
Received: 05 May 2004

Accepted: 03 September 2004

This article is available from: http://www.biomedcentral.com/I47I-2377/4/II

(c) 2004 Sadeghi et al; licensee BioMed Central Ltd.

This is an open-access article distributed under the terms of the Creative Commons Attribution License (http://creativecommons.org/licenses/by/2.0), which permits unrestricted use, distribution, and reproduction in any medium, provided the original work is properly cited.

\begin{abstract}
Background: central loop of the gastrocnemius-soleus $\mathrm{H}$-reflex latency $\left(T_{c}\right)$ that looks promising in the diagnosis of SI radiculopathy; has been investigated in a few studies and only two of them have focused on the constitutional factors affecting it. Although leg length has been shown to contribute to the $T_{c}$, the role of age is controversial. More confusing, none of the previously performed studies have used strict criteria to rule out subclinical neuropathy, so the results could be misleading. This study has been performed to determine the influence of leg length and age on $\mathrm{T}_{\mathrm{c}}$ among a carefully selected group of healthy volunteers.
\end{abstract}

Methods: after screening forty six volunteers by taking history, physical examination and a brief electrophysiologic study; forty of them were selected to enroll into the study. $T_{c}$ was obtained in all the study subjects and leg length and age were recorded for correlational analyses.

Results: this group was consisted of 26 males $(65 \%)$ and 14 females (35\%) with the age range of 19-65 years (Mean \pm SD: $37 \pm 10.7$ ) and leg length range of 29.5-43 centimeters (36.4 \pm 3.4 ).

Mean $\pm S D$ for $T_{c}$ was $6.78 \pm 0.3$. We found a significant correlation between $T_{c}$ and leg length $(P$ value $=0.003, r=0.49$ and confidence interval $95 \%=0.59-0.88$ ), no significant correlation was found between age and $T_{c}(P$ value $=0.48, r=0.1 \mathrm{I})$, also we obtained the regression equation as: $\mathrm{T}_{\mathrm{c}}=0.04 \mathrm{~L}+5.28$

Conclusions: in contrast to leg length, age was not correlated with $T_{c}$. Future studies are required to delineate other contributing factors to $T_{c}$.

\section{Background}

The H-Reflex evaluates $S_{1}$ radiculopathy [1]. The meas- ured latency, however, is neither specific nor sensitive for $S_{1}$ spinal nerve disease, as it traverses a long pathway. 
Pease et al [2] were the first who described the central loop of the gastrocnemius-soleus H-Reflex latency (Central $S_{1}$ loop latency or $\mathrm{T}_{\mathrm{c}}$ ) and suggested it might be promising in the diagnosis of $\mathrm{S} 1$ radiculopathy $[1,2]$.

Unfortunately, $\mathrm{T}_{\mathrm{c}}$ has been the subject of few studies, and as far as we know, only 5 articles [2-6] have been published on this issue so far. Among them, two have specifically evaluated the constitutional factors contributing to $\mathrm{T}_{c}$. Leg length has been shown to have a significant effect on $\mathrm{T}_{\mathrm{c}}$. It is controversial whether age entails a similar effect. Wang et al [5] found a direct correlation between age and Tc. This observation was not confirmed by Ghavanini et al in an independent study [6].

The current study has been performed to determine the influence of leg length and age on $\mathrm{T}_{\mathrm{c}}$.

\section{Methods}

We enrolled 46 volunteers to this study after obtaining informed consent. Following a standard history taking, all of them underwent physical examination and a brief electrophysiologic evaluation [7] to rule out asymptomatic polyneuropathy, including determination of: right peroneal nerve conduction velocity (PNCV), distal motor latency of right deep peroneal nerve (PDML) and standard gastrocnemius-soleus $H$ reflex latency $\left(T_{p}\right)$. We defined our exclusion criteria as: history of sacral radiculopathy or diabetes mellitus or any other disease with potential to cause neuropathy, any abnormality in neurological or musculoskeletal physical examination, or any of the following findings: PNCV less than $40 \mathrm{~m} / \mathrm{s}$, PDML more than $5 \mathrm{~ms}$ or prolonged $\mathrm{T}_{\mathrm{p}}$ (according to Braddom and Johnson's study [8].

Since we were supposed to rule out subclinical peripheral neuropathy and one component of the related electrodiagnostic study was measuring the distal motor latency for the deep peroneal nerve, the temperature at the dorsum of the foot was kept almost at $32^{\circ}$ Celsius.

The leg length of each person was measured as the distance from middle of the midpopliteal crease to the point at the most proximal part of the medial malleolus, in centimeters.

Subject's age to the nearest year was also recorded.

For obtaining $\mathrm{T}_{c^{\prime}}$, we used DANTEC 2000 c equipment, the sensitivity, sweep, and filter were set at: $0.2-1 \mathrm{mv} / \mathrm{div}, 5 \mathrm{~ms} /$ div, and $2-10,000^{\mathrm{Hz}}$ respectively. The technique was the same as described in the Literature [1,2]. Briefly: the volunteers lied prone on the examining table with the feet off the edge of the plinth. The $\mathrm{E}_{1}$ was placed at the middle of the line connecting midpoint of popliteal crease to the point at the most proximal part of the medial malleolus, and the $\mathrm{E}_{2}$ over the Achilles tendon (both were surface electrodes). The ground electrode was posed proximal to $\mathrm{E}_{1}$ and a disc electrode (anode) was placed on the anterior superior iliac spine. Then we inserted a monopolar $70 \mathrm{~mm}$ needle (cathode) at a point $1 \mathrm{~cm}$ medial to the posterior superior iliac spine, perpendicular to the frontal plane, and retracted it just a little after reaching the sacrum. Stimulus duration of $1 \mathrm{~ms}$ at $0.5 \mathrm{HZ}$ was then applied while increasing current intensity to obtain both $\mathrm{H}$ and $\mathrm{M}$ waves simultaneously. $\mathrm{M}$ wave is the earlier wave and $\mathrm{H}$ is the later one. The interpeak latency was measured in milliseconds $(\mathrm{ms})$ and recorded as $\mathrm{T}_{\mathrm{c}}$. This measurement was only performed on the right lower extremity.

Descriptive statistics were applied to depict Mean \pm SD of age, leg length and Tc. The independent effect of leg length and age on $\mathrm{T}_{\mathrm{c}}$ was assessed by multiple regression model. The analyses were performed using SPSS 10.0 software. Kolmogrov-Smirnov test was used for evaluating the normal distribution of the variables.

\section{Results}

From 46 subjects who volunteered to participate in this study; five cases were excluded after history taking and physical examination (two because of history of sacral radiculopathy, two because of diabetes mellitus and one because of asymmetry in ankle reflexes) and one case after electrophysiologic evaluation; thus we completed the study with 40 subjects. Subjects' characteristics are shown in table 1.

\section{Table I: subjects' characteristics}

\begin{tabular}{ll}
\hline Number of subjects & $40(26$ males, 14 females $)$ \\
Age range (years) & $19-65$ \\
Leg length (centimeters) & $29.5-43$ \\
$T_{c} \pm S D$ & $6.78 \pm 0.3$
\end{tabular}

The group consisted of 26 males (65\%) and 14 females (35\%). Kolmogrov-Smirnov test showed normal distribution of the variables.

You are provided with the information below: (Mean \pm SD) Age: $37.0 \pm 10.7$ years (range: $19-65$ ); leg length: 36.4 $\pm 3.4 \mathrm{~cm}$ (range: $29.5-43$ ); $\mathrm{Tc}=6.78 \pm 0.3$ There was a significant correlation between $\mathrm{T}_{\mathrm{c}}$ and leg length ( $\mathrm{P}$ value $=$ $0.003, \mathrm{r}=0.49$, CI 95\% = 0.59-0.88).

There was no correlation between $\mathrm{T}_{\mathrm{c}}$ and age $(\mathrm{p}$ value $=$ $0.48, r=0.11$ ) We also found this regression equation: $T_{c}$ $=0.04 \mathrm{~L}+5.28\left(\mathrm{~L}\right.$ is leg length in centimeters, $\mathrm{T}_{\mathrm{C}}$ is represented in milliseconds.) 
Table 2: comparing related studies

\begin{tabular}{|c|c|c|c|c|c|c|c|}
\hline & \multicolumn{4}{|c|}{ Subjects' characteristics } & \multicolumn{3}{|c|}{ Tc } \\
\hline & $\begin{array}{l}\text { Group size } \\
\text { (persons) }\end{array}$ & Mean age (yr) & Mean L (cm) & Mean $\mathrm{H}(\mathrm{cm})$ & Mean & $S D$ & $\begin{array}{c}\text { Correlation }(r) \\
\text { with A-H-L }\end{array}$ \\
\hline Present study & 40 & 37.0 & $\begin{array}{c}36.4 \mathrm{M}: 38.1 \\
\mathrm{~F}: 33.2\end{array}$ & $?$ & 6.78 & 0.3 & No-?-0.49 \\
\hline Pease et al [2] & 20 & $?$ & $?$ & $?$ & 7.0 & 0.3 & $?-?-?$ \\
\hline Zhu et al [3] & 60 & 43 & $?$ & 169 & 6.8 & 0.33 & No-0.54-? \\
\hline Wang et al $[5]^{*}$ & 40 & ? & $?$ & $?$ & $?$ & $?$ & $?-?-?$ \\
\hline $\begin{array}{c}\text { Ghavanini et al } \\
{[6]^{* *}}\end{array}$ & 39 & 41 & M:39.8 F:37.0 & M:I72.2 F:I59.5 & 6.9 & 0.4 & No-0.56-0.62 \\
\hline
\end{tabular}

A: age (yr); L: leg length (cm); H: height (cm); Tc: central loop of the H-reflex latency (ms); M: male; F: female; No: no correlation was found; ?: not reported

*: suggested a regression equation: $\mathrm{Tc}=0.02 \mathrm{~A}+0.03 \mathrm{H}+0.92$

**: Suggested two regression equations: $\mathrm{Tc}=0.05 \mathrm{IL}+4.928 ; \mathrm{Tc}=0.097 \mathrm{~T} \mathrm{p}+4.04$

\section{Discussion}

In this study we found a significant correlation between leg length and $\mathrm{Tc}$, but we were unable to show such a relation between age and $\mathrm{T}_{\mathrm{c}}$.

Pease et al were the first, studied $\mathrm{T}_{\mathrm{c}}[2,4]$, and reported Mean \pm SD of $7 \pm 0.3^{\mathrm{ms}}$ which is very close to our results $(\mathrm{Tc}=6.78 \pm 0.3)$. They didn't specifically consider the leg length, age or any other potential confounding variables to $\mathrm{T}_{c}$.

Zhu et al [3] evaluated 60 persons and reported Mean $\mathrm{T}_{\mathrm{c}}$ : $6.8 \mathrm{~ms}$ and its SD: $0.33 \mathrm{~ms}$, again close to our results. They also reported that $\mathrm{T}_{\mathrm{c}}$ and person's height were correlated but didn't study any correlation between age and $\mathrm{T}_{\mathrm{c}}$.

Wang et al [5] evaluated 40 persons and found this regression equation:

$\mathrm{T}_{\mathrm{C}}=0.02 \mathrm{~A}+0.003 \mathrm{H}+0.92(\mathrm{H}:$ Height and A: Age), and stated that age is a contributing factor on $\mathrm{T}_{\mathrm{C}}$.

Another research was performed by Ghavanini et al [6], in which 39 subjects were evaluated. The reported $T_{c} \pm S D$ was $6.9 \pm 0.4$; two regression equations were also suggested: $\mathrm{T}_{\mathrm{c}}=0.097 \mathrm{Tp}+4.045$ and $\mathrm{Tc}=0.051 \mathrm{~L}+4.92(\mathrm{~L}=\mathrm{leg}$ length in centimeters); results are close to ours, and age was not found to affect $\mathrm{T}_{\mathrm{c}}$.

A summary of the above data plus detailed demographic data are provided in the table 2 .

\section{Limitations}

In this study we focused on age and leg length as potential contributing factors on the $\mathrm{T}_{\mathrm{c}}$. we didn't control, rand- omize or observe other possible confounding (contributing) factors with potential to affect this parameter.

We observed a significant correlation between leg length and $\mathrm{T}_{\mathrm{c}}(\mathrm{P}$ value $=0.003, \mathrm{r}=0.49, \mathrm{CI} 95 \%=0.59-0.88)$, that is compatible to a previous published work [3] $(\mathrm{r}=$ 0.54 , $\mathrm{p}$ value less than 0.01 ).

Had we found any association between $T_{c}$ and age, the question might have been raised that subclinical neuropathy of old age could have been contributive; obviously, this is not the case in our study.

Although F-wave has been used to evaluate the possibility of proximal neuropathy; it was not measured in this study. Alternatively, we measured H-reflex latency to exclude proximal neuropathy [11].

It should be emphasized that noninvasive methodologies for the diagnosis of subclinical S1 radiculopathy are now available [12]. It is also acceptable to stimulate the S1 spinal nerve at the $S 1$ foramen by magnet, instead of deep tissue needling; nevertheless, we used more popular techniques for this study.

\section{Conclusions}

We found that between age and leg length, only the latter can affect $T_{c}$. It may be reasonable to consider leg length for calculating $\mathrm{T}_{\mathrm{c}}$ and to "narrow" the normal limits.

Further studies with larger sample sizes are required for detecting other contributing factors and standardizing $T_{c}$ according to leg length.

\section{Competing interests}

None declared. 


\section{Abbreviations}

$\mathrm{T}_{\mathrm{c}}$ : central loop of the gastrocnemius-soleus H-Reflex latency

$\mathrm{T}_{\mathrm{p}}$ : gastrocnemius-soleus H-Reflex latency

PNCV: right peroneal nerve conduction velocity

PDML: right peroneal nerve distal motor latency

\section{Authors' contribution}

SS: examining the cases, calculation of $\mathrm{TC}$, writing the paper.

MRAG: suggesting the research, supervision and helping with calculation of TC.

AA: examining the cases, calculation of TC

PJ: statistical consultant (data analysis)

\section{Acknowledgements}

The authors would like to thank:

Ali Bidari, MD, assistant professor of rheumatology, Iran university of medical sciences, for his great help in the revision of the manuscript

Mojtaba Mahjoob, MD, resident of surgery, and Masoome Rostamzade, English instructor, for translating the manuscript.

\section{References}

I. Dumitru D, ed: Electrodiagnostic medicine. 2nd edition. Philadelphia: Hanley and Belfus,inc.; 2002.

2. Pease WS, Kozakiewicz R, Johnson EW: Central loop of the $\mathbf{H}$ reflex : Normal values and use in $\mathrm{SI}$ radiculopathy. Am J phys Med Rehabil 1997, 76(3): |82-184.

3. Zhu Y, Starr A, Haldeman S, Chu JK, Sugerman RA: Soleus H reflex to $\mathrm{SI}$ nerve root stimulation. Electroencephalogr Clin Neurophysiol 1998, 109:10-14.

4. Pease WS, Lagattuta FP, Johnson EW: Spinal nerve stimulation in S, radiculopathy. Am J Phys Med Rehabil 1990, 69(2):77-80.

5. Wang R, Liu X, Guo Y: Hoffmann reflex elicited by magnetic stimulation of $S_{1}$ nerve roots in the diagnosis of diabetic radiculopathy. Zhonghua Yi xue Za Zhi 1998, 78(7):50I-503. chinese

6. Ghavanini MR, Ghadi RS, Ghavanini AA: The central loop of the $\mathbf{H}$

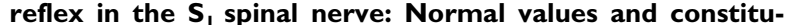
tional influencing factors. Electromyogr clin neurophysiol 200I, 4 I(6):259-262.

7. Frigns CJM, Laman DM, Van Dujin MAJ, van-Duijn $\mathrm{H}$ : Normal values of patellar and ankle tendon reflex latencies. Clin Neurol Neurosurg 1997, 99:31-36.

8. Braddom RL, Johnson EW: Standardization of $\mathbf{H}$ reflex and diagnostic use in $\mathbf{S}_{\text {I }}$ radiculopathy. Arch phys Med Rehabil 1974, 55:161-166.

9. Strakowski JA, Redd DD, Johnson EW, Pease WS: H-reflex and F wave latencies to soleus normal values and side to side differences. Am J Phys Med Rehabil 200I, 80:49I-493.

10. Buschbacher RM: Normal range for $\mathbf{H}$-reflex recording from the calf muscles. Am J Phys Med Rehabil 1999, 78(6 Suppl):S75-79.

II. Braddom RL, Johnson EW: Standardization of the $\mathbf{H}$ reflex and diagnostic use in s I radiculopathy. Arch phys med rehabil 1974, 55:16I-166.

12. Mazzocchio R, Scarfo GB, Mariottini A, Muzii FM, Palma L: recruitment curve of the soleus $H$ reflex in chronic back pain and lumbosacral radiculopathy. BMC musculoskeletal disorders 200I, 2:4.

Pre-publication history

The pre-publication history for this paper can be accessed here:

http://www.biomedcentral.com/1471-2377/4/11/prepub
Publish with Biomed Central and every scientist can read your work free of charge

"BioMed Central will be the most significant development for disseminating the results of biomedical research in our lifetime. "

Sir Paul Nurse, Cancer Research UK

Your research papers will be:

- available free of charge to the entire biomedical community

- peer reviewed and published immediately upon acceptance

- cited in PubMed and archived on PubMed Central

- yours - you keep the copyright 